\title{
ACTIVITY OF COMMERCIAL STILL WATERS FROM VOLATILE OILS PRODUCTION AGAINST WOOD DECAY FUNGI
}

Selim Şen, Mesut Yalçın ${ }^{1}$

\begin{abstract}
The antifungal properties of some commercial plant waters obtained as side products in producing distilled oils were investigated. Paper disc samples were impregnated with various plant waters and exposed to wood decay fungi for 3 months in Petri dishes. Ten types of plant water (Laurus nobilis, Calluna vulgaris, Lavandula stoechas, Thymus vulgaris, Myrtus communis, Eucalyptus globulus, Mentha pulegium, Urtica dioica, Melissa officinalis, and Matricaria chamomilla were examined. Seven fungi were used (Phanerochaete chrysosporium, Ceriporiopsis subvermisphora, Gloeophyllum trabeum, Trametes versicolor, Oligoporus placenta, Pleurotus ostreatus, and Coniophora puteana). The antifungal activities of the plant waters obtained from thyme and lavender were particularly high.
\end{abstract}

Keywords: Medicinal plants, distillation water, antifungal activity, wood protection

\section{INTRODUCTION}

Wood, naturally occurring polymer composite, is principal composed of cellulose, lignin, hemicelluloses and extractive materials. Due to its biological nature, unprotected wood is susceptible to biological attacks, which reduces its mechanical and physical properties (Chang et al. 2002). Developing methods that prolong the service life of wood has always been the interest of wood researchers. Environmentally, using naturally compounds in highly durable tree species is the most appropriate approaches in wood protection industry while preserving the environment (Chang et al.2000). Extraction of natural compounds having specific antimicrobial and insecticide properties from plants is an important method of natural wood product research (Morita et al. 1997, Chang et al. 1999, Cheng et al. 2004). Sen (2001) determined that plant extracts obtained from some Turkish commercial plants had antifungal and insecticide properties against to wood deteriorate fungus and insect. Essential oils are known for their natural components of hydrocarbons (monoterpen, diterpen), oxygen- (alcohols, aldehydes, ketones, carboxylic acids, esters, and lactones) and sulfurcontaining organic substances of plants (Voda et al. 2003). Their constituents and derivatives have long been studied for their applications as antimicrobial and antifungal properties in the area of food preservation and pharmaceutical industries. Furthermore their use in cosmetics, essential oils and constituents has a long history of applications as antimicrobial agents. Contemporary applications are found in the areas of food preservation and in the manufacturing of medicinal antimicrobial agents and disinfectants. Eugenol, thymol, and carvacrol, for example, are well known phenolic representatives found in clove, thyme, and oregano oils and have been demonstrated to have an inhibitory activity against both bacteria (Hao et al. 1998, Ultee et al. 1998, Didry et al. 1994) and fungi (Scora and Scora 1998, Mahmoud 1994). In the past ten years, more interest has focused on the potential applications of natural plant extracts as wood protection agents to prevent mold and fungal growth on in-service wood (Yang and Clausen 2007).

${ }^{1}$ Duzce University, Dept. of Forest Products Engineering, 81620 Düzce, Turkey

Corresponding author: selimsen@duzce.edu.tr

Received: 22.07. 2009. Accepted: 04.05. 2010 
In the recent years, antimicrobial and insecticidal properties of volatile oils and extracts obtained from leaves, barks, and the other part of the wood and plants have been examined for the wood protection industry. There have been some studies that discuss the antimicrobial, antitermitic (Chang and Chang 2002, Wang et al. 2005), and antipesticide (Chang et al. 2001) activities of Cinamomum osmophloeum. Wang et al.(2005) determined that volatile oils from leaves of Cinnamomum osmophloeum had antifungal effects against the white rot fungus Trametes versicolor; and the brown rot fungus Laetiporus sulphureus. Inhibition zones, determined in Petri dishes, of cinnamon leaf oils were $18 \%$ against $T$. versicolor and $34 \%$ against $L$. sulphureus. The interest in volatile oils obtained from cinnamon leaves may derive from its potential use as a fumigant against wood deterioration. Yang and Clausen (2007) investigated the antifungal activities of thyme and Egyptian geranium oils against three mold fungi (Trichoderma viride, Penicillium chrysogenum, and Aspergillus niger) in yellow pinewood samples. They found that plant components were effective against mold fungi that could stain wood. If wood materials are impregnated with these effective components, they may be useful in some construction applications such as timber roofs and beams.

In recently years, there have been made some studies about antifungal and antibacterial activities of volatile oils in Turkey. Diğrak et al. (2001) examined the antimicrobial properties of some medicinal plants growing in Turkey (Rhus coriaria, Stachys annua, Stachys pumilia, Laurus nobilis, Allium neapolitanum, Salvia viridis, Nicotina rustica) against Bacillus sp., Escherichia coli, Enterobacter aerogenes, Pseudomonas aeruginosa, Staphylococcus aureus, Listeria monocytogenes, Micrococcus luteus, and Candida sp. and found that the effects against Bacillus sp. of R. coriaria extracts were strong.

Kartal et al. (2006) studied the effect of essential oil compounds and plant extracts on decay and termite resistance of wood. In the study, the formulations with cinnamic acid, ferulic acid and cinnamaldehyde showed strong antifungal activities. Squalene and wood tar oil containing formulation were also effective against wood degrading fungi in the test. Results suggested that essential oils and plant extracts might be important to develop new wood preservatives that are less harmful to the environment and humans than recently available ones.

In this study, the antifungal properties of some commercial plant waters obtained as side products in producing distilled oils were investigated. In practice, volatile oils are expensive products for use in the wood protection area because they have other competing applications in the health and cosmetic industry (Baytop 1999). However, distillation waters (a by-product) containing some level of volatile oils may offer an inexpensive alternative source. In this study, the antifungal effects of some commercially available plant waters were studied against wood decay fungi.

\section{MATERIAL AND METHOD}

\section{Essential oils}

The compounds used in the study were obtained from the Mecitefendi ${ }^{\circledR}$ Inc. İzmir-Turkey. The plant waters [Calluna vulgaris (heather leaf), Eucalyptus globulus (eucalyptus), Laurus nobilis L. (laurel leaf), Lavandula stoechas L. (lavender), Matricaria chamomilla L. (chamomile flowers), Melissa officinalis L. (balm leaf), Mentha pulegium L. (Penn royal leaf), Myrtus communis L. (myrtle leaf), Thymus vulgaris (thyme), and Urtica dioica L. (nettle leaf)]. The distillation process at Mecitefendi Inc. involves distilled water and fresh plant material at a ratio of 1:1 (w/w) in the production of volatile oils. During the production of distilled oils, dissolved volatile oils at a level of $0.3-0.8 \%$ typically remain in distillation waters as a by-product (Anon, 2009). The distilled drinking water (Figure 1) were taken during production as a by-product, diluted with pure water five times and stored at $5{ }^{\circ} \mathrm{C}$. 


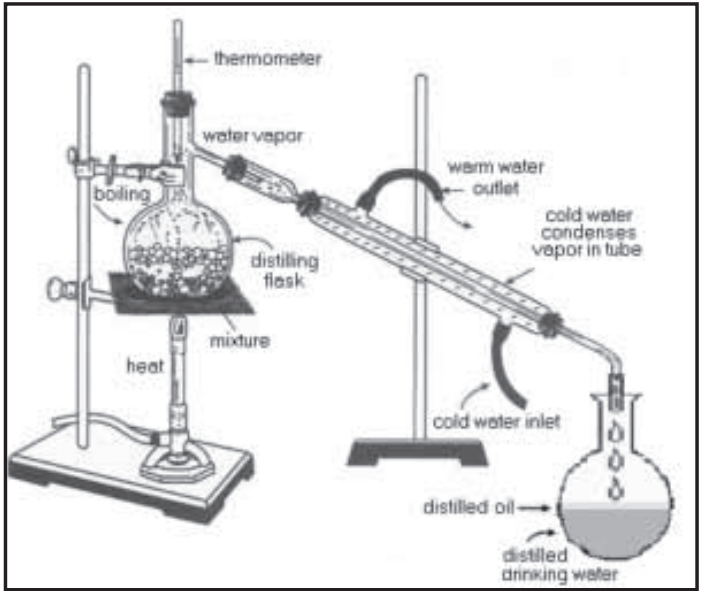

Figure 1. Generation of distilled drinking water as a by-product from volatile oil production

\section{Preparing of test specimens}

The tests were made on disc samples prepared from thermomechanical pulp paper due to the composition of termomechanical pulp paper is similar to wood chemical composition and can provide rapid results (Wilkinson 1979, Bozkurt et al. 1993). The test papers were treated with plant waters $(3,5 \mathrm{ml}$ per disc paper), without dilution and were placed in sterilized petri dishes ( $9 \mathrm{~cm}$ diameter).

\section{Fungal strains}

In this study, three brown rot (Coniophora puteana FPRL 11E, Gloeophyllum trabeum Mad-617-R, Oligoporus placenta AJ416068) and four white rot fungus (Ceriporiopsis subvermisphora FP-90031-Sp, Phanerochaete chrysosporium BKM-F-1767, Pleurotus ostreatus FP-101798-Sp, Trametes versicolor MAD-697) were used were provided by the US Forest Products Laboratory in Madison, WI.

\section{Antifungal assays}

After paper discs were treated in petri dishes were sterilized in autoclave, the samples were inoculated with test fungus. All specimens were incubated in the dark at $26 \pm 2{ }^{\circ} \mathrm{C}$ and $70 \%$ relative humidity for 3 weeks. Following incubation, the mycelium of fungi reached the edges of the untreated control dishes, the antifungal effects were evaluated. Surface mycelia growth was rated visually by percentage of surface coverage (Figure 2). Antifungal effects were marked with plus (+) and minus (-) signs, according to the degree of antifungal activity (++++ no visible growth of mycelium, +++ mycelium has covered about $25 \%,++$ about $50 \%,+$ about $75 \%$, - about $100 \%$ of the petri dishes) (Yang and Clausen 2007, AWPA 2006, TS ENV 839/2006). In addition, prepared control samples impregnated with pure water and a commercial fungicide chromated copper borate (CCB, $1 \%$ concentration) was used as the comparison.

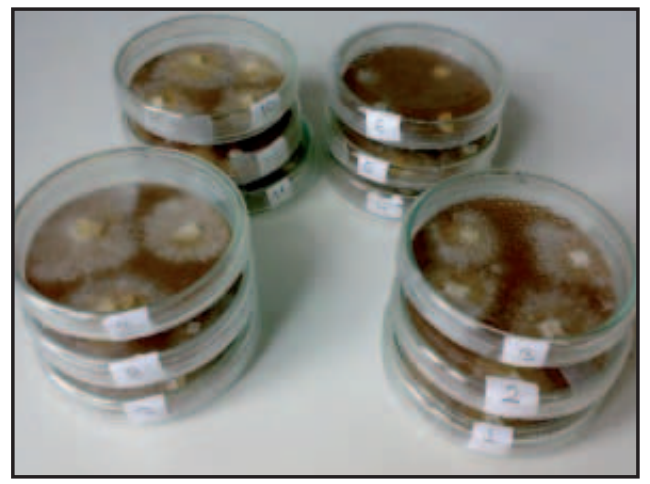

Figure 2. Mycelium growing on the surfaces of disc papers in petri dishes 


\section{RESULTS AND DISCUSSION}

Distilled waters prepared from 10 different plants were examined to evaluate their antifungal activity against seven species of wood decay fungi. The papers were followed with regard to the development of mycelium growth for 3 weeks. Table 1 shows the results of the antifungal assay of the brown rot test fungus Coniophora puteana, Gloeophyllum trabeum, Oligoporus placenta, and white rot test fungus Ceriporiopsis subvermisphora, Phanerochaete chrysosporium, Pleurotus ostreatus, and Trametes versicolor respectively.

Table 1. Antifungal effects of distillation waters against to wood decay fungi

\begin{tabular}{|l|c|c|c|c|c|c|c|c|}
\hline Herbal source & $\begin{array}{c}\text { Distillation } \\
\text { liquid }\end{array}$ & Cp & Gt & Op & Cs & Pc & Po & Tv \\
\hline Laurus nobilis & Laurel leaf & + & + & ++ & ++ & ++ & ++ & ++ \\
\hline Calluna vulgaris & Heather leaf & - & - & ++ & + & - & - & + \\
\hline Lavandula stoechas & Lavender & ++ & ++ & +++ & ++ & ++ & ++ & +++ \\
\hline Thymus vulgaris & Thyme & ++ & +++ & +++ & +++ & ++++ & ++++ & +++ \\
\hline Myrtus communis & Myrtle leaf & + & + & +++ & ++ & ++ & ++ & +++ \\
\hline Eucalyptus globules & Eucalyptus & + & + & ++ & ++ & + & + & + \\
\hline Mentha pulegium & Penn royal leaf & + & - & ++ & ++ & + & + & ++ \\
\hline Urtica dioica & Nettle leaf & + & + & ++ & +++ & + & + & ++ \\
\hline Melissa officinalis & Balm leaf & - & - & ++ & + & - & - & + \\
\hline Matricaria chamomilla & Cham. flowers & + & - & + & ++ & + & + & ++ \\
\hline Control samples & pure water & - & - & - & - & - & - & - \\
\hline impregnated with & CCB (1\%) & ++++ & +++ & +++ & ++ & ++ & ++++ & ++++ \\
\hline
\end{tabular}

+++ No visible growth of mycelium. +++ Mycelium has covered about $25 \%,++$ about $50 \%$, + about $75 \%$, about $100 \%$ of the Petri dishes.

Antifungal effects of the plant waters against to white and brown rot fungus were shown Figure 3 and 4. The waters from plants rich in essential oil content had generally higher antifungal activity against these wood decay fungi. The waters from thyme, myrtle leaf, and lavender plants had especially high antifungal activity. Of those tested, thyme water had the highest antifungal effect, followed by lavender. Yang and Clausen (2007) studied the essential oils and observed that the thyme oil inhibited growth of all test fungus (Trichoderma viride, Penicillium chrysogenum, and Aspergillus niger). And The essential oil of Lavandula bipinnata was screened for antimicrobial activity by disc diffusion assay and minimum inhibitory concentration (MIC) against some bacteria and fungus (Hanamanthagouda et al.2009). The waters from laurel leaf, myrtle leaf, eucalyptus leaf, and chamomile showed a moderate degree of antifungal activity, and waters from balm leaf and heather leaf showed little antifungal activity. Mycelium growth with most fungi was clearly evident on samples impregnated with the waters from heather leaf, penn royal leaf, and balm leaf. 


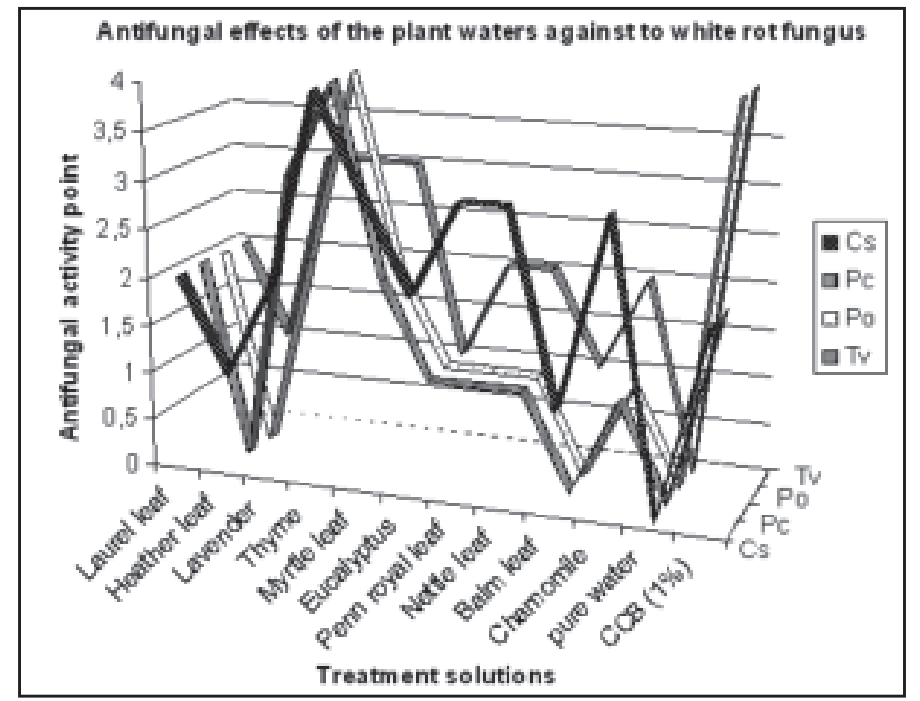

Figure 3. Antifungal effects of the plant waters against to white rot fungus

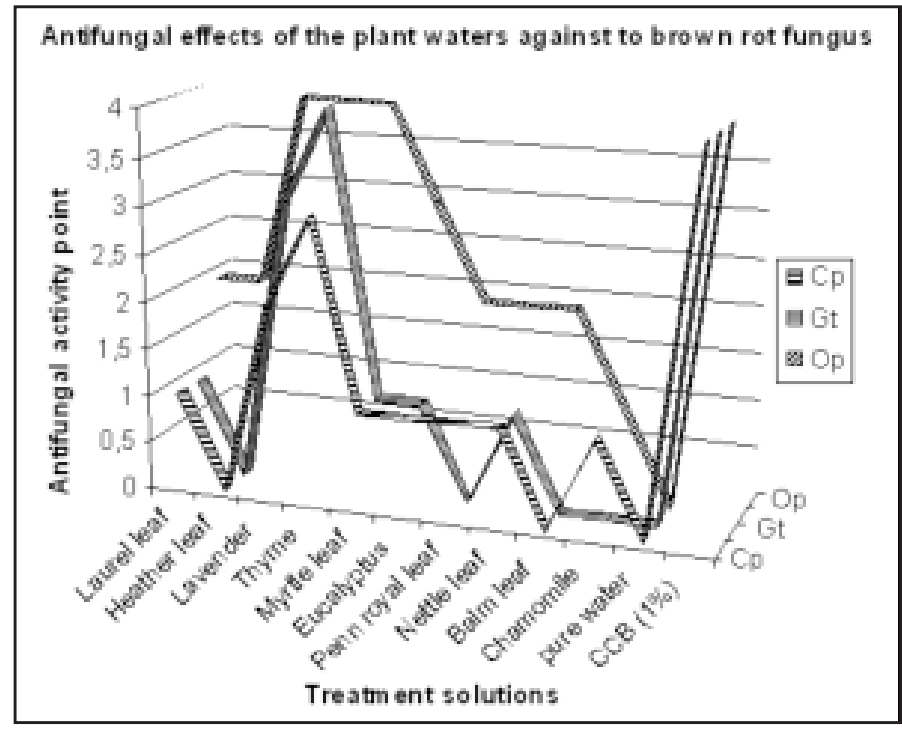

Figure 4. Antifungal effects of the plant waters against to brown rot fungus

The mycelium growth of C. puteana, G. trabeum, P. chrysosporium, and P. ostreatus was intensive on test samples, except with thymus and lavender water. C. subvermisphora, O. placenta, and $T$. versicolor showed generally higher mycelium growth than the other species. C. puteana, $G$. trabeum, $P$. chrysosporium, and $P$. ostreatus showed generally less mycelium growth than the other fungi. Control samples impregnated with pure water showed good growth. $C$. subvermisphora and P. chryosporium were the most resistant fungi against the CCB preservative.

\section{CONCLUSIONS}

This study showed that the antifungal effects of some diluted distillation drinking waters were quite considerable, because of the soluble volatile oils they contained. The antifungal activities of waters from plants that are not rich in volatile oils showed variable results. This study illustrates 
that distilled waters (heather leaf, eucalyptus, laurel leaf, lavender, chamomile flowers, balm leaf, penn royal leaf, myrtle leaf, thyme, and nettle leaf) may be useful in the area of wood protection as fungicides. This should be studied with other fungi and molds on wooden test blocks in more detail. Such experiments are important in terms of validating the general applicability of the method in practice and in determining the most economical and effective concentrations of the distillation waters.

The use of volatile oils is not practical for routine wood protection because of their high value as medicines and cosmetics, although their use may be warranted in special circumstances, such as the protection of historical or cultural wooden structures or archaeological wood and its repair. In contrast, still waters are plentiful and should be considered for possible applications in the wood protection industry instead of using the volatile oils themselves.

\section{REFERENCES}

Anonymous. 2009. Production of distilled oil and still drinking water. Brochure. Izmir-Turkey. (www. mecitefendi.com.tr)

AWPA 2006. American Wood-preservers' Association Standard. Standard Method of Testing Wood Preservatives by Laboratory Soil - Block Cultures. AWPA E10-06. Birmingham, AL. pp. 313-321

Baytop, T. 1999. Therapy with Plants in Turkey, ISBN:975-420-021-1, İstanbul.

Bozkurt, Y.; Göker, Y.; Erdin, N. 1993. Wood Preservation Technique. Istanbul University, No: $3779 / 425,429$ s.

Chang, H.T.; Yeh, T.F.; Chang, S.T. 2002. Comparisons of chemical characteristic variations for photodegraded softwood and hardwood with/without polyurethane clear coatings. Polym. Degrad. Stab. 77:129-135.

Chang, S.T.; Wang, S.Y.; Wu, C.L.; Su, Y.C.; Kuo, Y.H. 1999. Antifungal compounds in the ethyl acetate soluble fraction of the extractives of Taiwania (Taiwania cryptomerioides Hayata) heartwood. Holzforschung 53: 487-490.

Chang, S.T.; Chen, P.F.; Chang, S.C. 2001. Antibacterial activity of leaf essential oils and their constituents from Cinnamomum osmophloeum, J. Ethnopharmacol. 77: 123-127.

Chang, S. T.; Wang, S. Y.; Wu, C. L.; Chen, P. F.; Kuo, Y. H. 1999. Comparison of the antifungal activity of cadinane skeletal sesquiterpenoids from Taiwania (Taiwania cryptomerioides Hayata) heartwood. Holzforschung 54:241-245.

Chang, S.T. ; Cheng S.S. 2002. Antitermitic activity of leaf essential oils and components from Cinnamomum osmophleum. J Agric Food Chem 50: 1389-1392

Cheng, S.S.; Wu, C.L.; Chang, H.T.; Kao, Y.T.; Chang, S.T. 2004. Antitermitic and antifungal activities of essential oil of Calosedrus formasana leaf and its composition. Journal of Chemical Ecology 30(10): 1957-1967.

Diğrak, M.; Alma, M.H.; Ilçim, A. 2001. Antibacterial and antifungal activities of Turkish medicinal plants. Pharmaceutical Biology 39(5): 346-350

Didry, N.; Dubreuil,L.; Pinkas, M.1994. Activity of thymol, carvacrol, cinnamaldehyde and eugenol on oral bacteria. Pharmaceutica Acta Helvetiae 69: 25-28. 
Hanamanthagouda, M.S.; Kakkalameli, S.B.; Naik, P.M.; Nagella, P.; Seetharamareddy, H.R.; Murthy, H.N. 2009. Essential oils of Lavandula bipinnata and their antimicrobial activities. Food Chemistry 118: 836-839

Hao, Y.Y.; Brackett, R.E.; Doyle, M.P. 1998. Escacy of plant extracts in inhibiting Aeromonas hydrophila and Lysteria monocytogenes in refrigerated, cooked poultry. Food Microbiology 15: $367-378$.

Kartal, S. N.; Hwang, W-J.; Imamura, Y.; Sekine, Y. 2006. Effect of essential oil compounds and plant extracts on decay and termite resistance of wood. Holz Roh Werktoff 64 (6): 455-461

Mahmoud, A. L.E. 1994. Antifungal action and antia:atoxigenic properties of some essential oil constituents. Letters in Applied Microbiology 19: 110-113.

Morita, S.I.; Hidaka, T.; Yatagai, M. 1997. Antifungal components of the extactives of yakusugi (Crypotomeria japonica D. Don). Wood Preservation 23:11-19.

Scora, K.M.; Scora, R.W. 1998. Effect of volatiles on mycelium growth of Penicillium digitatum, P. italicum, and P. ulaiense. Journal of Basic Microbiology 38: 405-413.

SEN, S. 2001. Determination of wood preservative activities of plant phenolics. Ph.D. Thesis. Zonguldak Karaelmas University. Graduate school of natural and applied sciences. Department of Forestry Industrial Engineering, Bartın, p. 300.

TS ENV 839/2006. Turkish standards. Wood preservatives - determination of the preventive efficacy against wood destroying Basidiomycetes fungi.

Ultee,A.; Gorris, L.G.M.; Smid, E.J. 1998. Bactericidal activity of carvacrol towards the food-borne pathogen Bacillus cereus. Journal of Applied Microbiology 85, 211-218.

Voda,K.; Boha B.; Vrta-Cnika M.; Pohleven, F. 2003. Effect of the antifungal activity of oxygenated aromatic essential oil compounds on the white-rot Trametes versicolor and the brown-rot Coniophora puteana. International Biodeterioration \& Biodegradation 51: 51 - 59

Wang, S.Y.; Chen, P.F.; Chang, S.T. 2005. Antifungal activities of essential oils and their constituents from indigenous cinnamon (Cinnamomum osmophloeum) leaves against wood decay fungi. Bioresource Technology 96: 813-818.

Wilkinson, JG. 1979. Industrial Timber Preservation. The Rentokil Library. Associated Business Press, London.

Yang, V.W.; Clausen, C.A. 2007. Antifungal effects of essential oils on southern yellow pine. International Biodeterioration and Biodegradation 59: 302-306. 
